\title{
Analysis of the geographic distribution and relationships among Peruvian wild species of Arracacia
}

\author{
R. Blas $\cdot$ M. Hermann $\cdot$ J.-P. Baudoin
}

Received: 28 July 2006/ Accepted: 2 July 2007 / Published online: 15 August 2007

(C) Springer Science+Business Media B.V. 2007

\begin{abstract}
Relationships between Arracacia species were studied according to 28 morphological discriminant characters, in 90 accessions: 83 Arracacia (Arracacia elata, A. incisa and A. xanthorrhiza), and seven accessions of Neonelsonia acuminata, which has been confused with A. elata. The geographic distribution of the Arracacia species was determined from the passport data of the 90 accessions. A. elata was clearly differentiated from $N$. acuminata according to morphological characteristics. The species $A$. incisa was more closely related to A. xanthorrhiza. Within A. xanthorrhiza two forms, monocarpic, and polycarpic, were identified. The distribution of wild Arracacia species in Peru is characterized by two main ecological zones: (1) a dry zone, like the western Yunga and western and inter-Andean valleys of the Quechua region (with seasonal rain from November to March), where the species A. incisa and
\end{abstract}

\section{R. Blas $(\square)$}

Universidad Nacional Agraria, La Molina, Ap. 456, Lima 12, Peru

e-mail: rblas@lamolina.edu.pe

\section{Hermann}

International Plant Genetic Resources Institute (IPGRI), Regional Office for the Americas, Ap. 6713, Cali, Colombia

\section{J.-P.Baudoin}

Faculté Universitaire des Sciences Agronomiques de Gembloux, Passage des Déportés, 2, Gembloux 5030, Belgique
A. xanthorrhiza are present, and (2) a humid zone, like the Eastern Quechua where A. elata is adapted. These informations could be useful to establish strategies for in situ and ex situ conservation and management of germplasm.

Keywords Arracacia . Ecology .

Geographic distribution - Neonelsonia acuminata .

Peru · Plant genetic resources · Taxonomy

\section{Introduction}

The species of Arracacia Bancroft are either perennial or biannual plants, characterized by the presence or absence of storage roots. They grow from Mexico to Bolivia and are adapted to altitudes ranging from 600 to 3,600 m (Hodge 1954; National Research Council 1989; Constance 1997; Hermann 1997). According to Knudsen (2003), about 30 species of Arracacia are presently recognized, and ten are distributed in the mountainous Andean region of South America (Venezuela, Colombia, Ecuador, Peru, and Bolivia).

Over the last 50 years, six species were reported from Peru: A. xanthorrhiza Bancroft, A. peruviana (Wolff) Const., A. andina Britt, A. equatorialis Const., A. incisa Wolff, and A. elata Wolff (Constance 1949; Brako and Zarucchi 1993). The last analysis of Peruvian species conducted by Blas (2005) reported only three species: A. elata, 
A. incisa, and A. xanthorrhiza. However, there are no reliable data about their geographic distribution and relationships, which set a problem for future collecting missions and in situ and ex situ germplasm conservation.

This study of the Arracacia genus in Peru was conducted with two goals: first, to formulate more precise hypotheses about the relationships among Peruvian Arracacia species and, second, to identify the distribution and ecology of Arracacia in Peru. These two goals are necessary to develop strategies for germplasm management of Arracacia spp. in the Andean region.

\section{Materials and methods}

\section{Plant material}

Plant material from 90 accessions of Peruvian arracacha was collected from 15 Peruvian Departments (Table 1). This collection included: 83 accessions of Arracacia wild species (A. elata, A. incisa, and A. xanthorrhiza) and seven accessions of Neonelsonia acuminata (Benth.) Coulter et Rose, often confused with A. elata or classified as $A$. acuminata Benth.

\section{Morphological analysis}

Wild forms were evaluated in the field at the time of collection and/or in the laboratory from herbarium material. Morphological characteristics from five wild plants per accession were recorded using the 28 descriptors previously selected (Table 2) (Blas 2005), from which 17 are double state and multistate qualitative variables and 11 are quantitative variables. These descriptors include characteristics of the storage roots, cormels, leaves, flowers, and fruits. Characters of the above-ground plant parts were recorded at flowering time, and characters of the underground parts were recorded immediately after uprooting the samples. The color of some plant organs was described according to the color chart of the Royal Horticultural Society (1995). States of shape characters were identified according to the plant identification terminology (Lindley 1951; Harris and Harris 2001). To analyze statistically each accession, we used the mode for qualitative characters and the mean for the quantitative characters.

Geographic distribution

Passport data (latitude, longitude, and altitude) were recorded for the 90 accessions of wild Arracacia species (Table 1). In addition, for each collection site, climate data (temperature and precipitation) were obtained from DIVA-GIS data base (Hijmans et al. 2002).

Data analysis

Data were compiled in a matrix of 90 accessions (or considered as the Operational Taxonomic UnitOTU) $\times 28$ descriptors. Each descriptor was analyzed using basic descriptive statistics with the help of Minitab 13.1 software. For multivariate analysis, the matrix data were standardized. The average taxonomic distances were then computed with NTSYS-pc 2.1 software (Rohlf 1994, 2000). With this matrix dendrograms were generated using "Unweighted Pair-group Method using Arithmetic Averages (UPGMA)" according to the Sequential Agglomerative Hierarchical Nested cluster analysis (SAHN) clustering program included in NTSYS-pc 2.1 (Rohlf 2000).

For the analysis of geographic distributions of species, all coordinate data (latitude and longitude) in the sexagesimal system were transformed to the decimal system. Data were analyzed and visualized by the geographic information system (DIVA-GIS 2.4: http:/gis.cip.org/gis/tools/diva.htm) software (Hijmans et al. 2002). This software is aimed specifically at the analysis of biodiversity data, and allows the mapping of species and extraction of climate data for collecting sites.

\section{Results and discussion}

Genetic relationships of Peruvian wild species of Arracacia

The 90 analyzed accessions were classified according to the 28 selected descriptors, indicating two main 


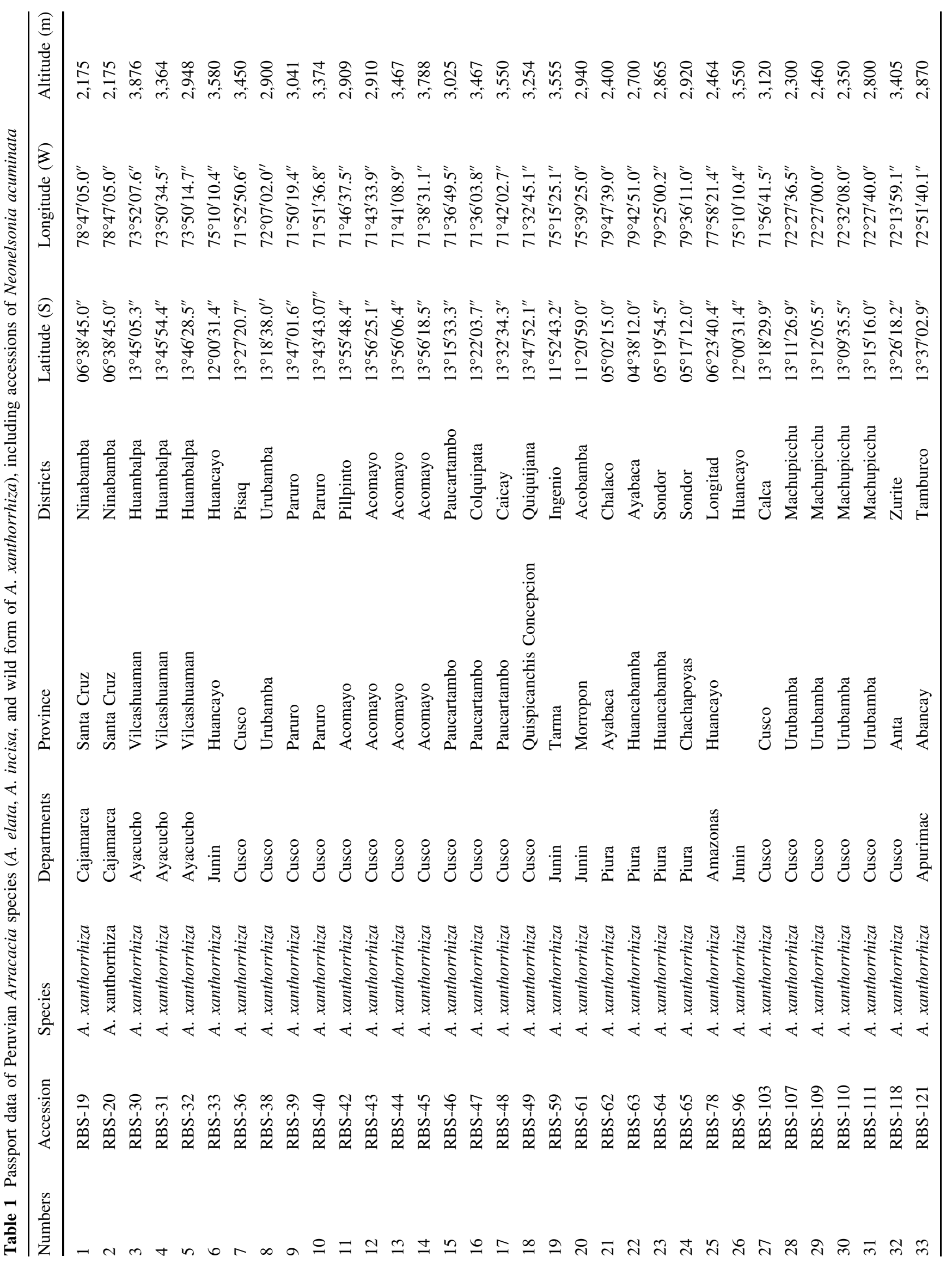




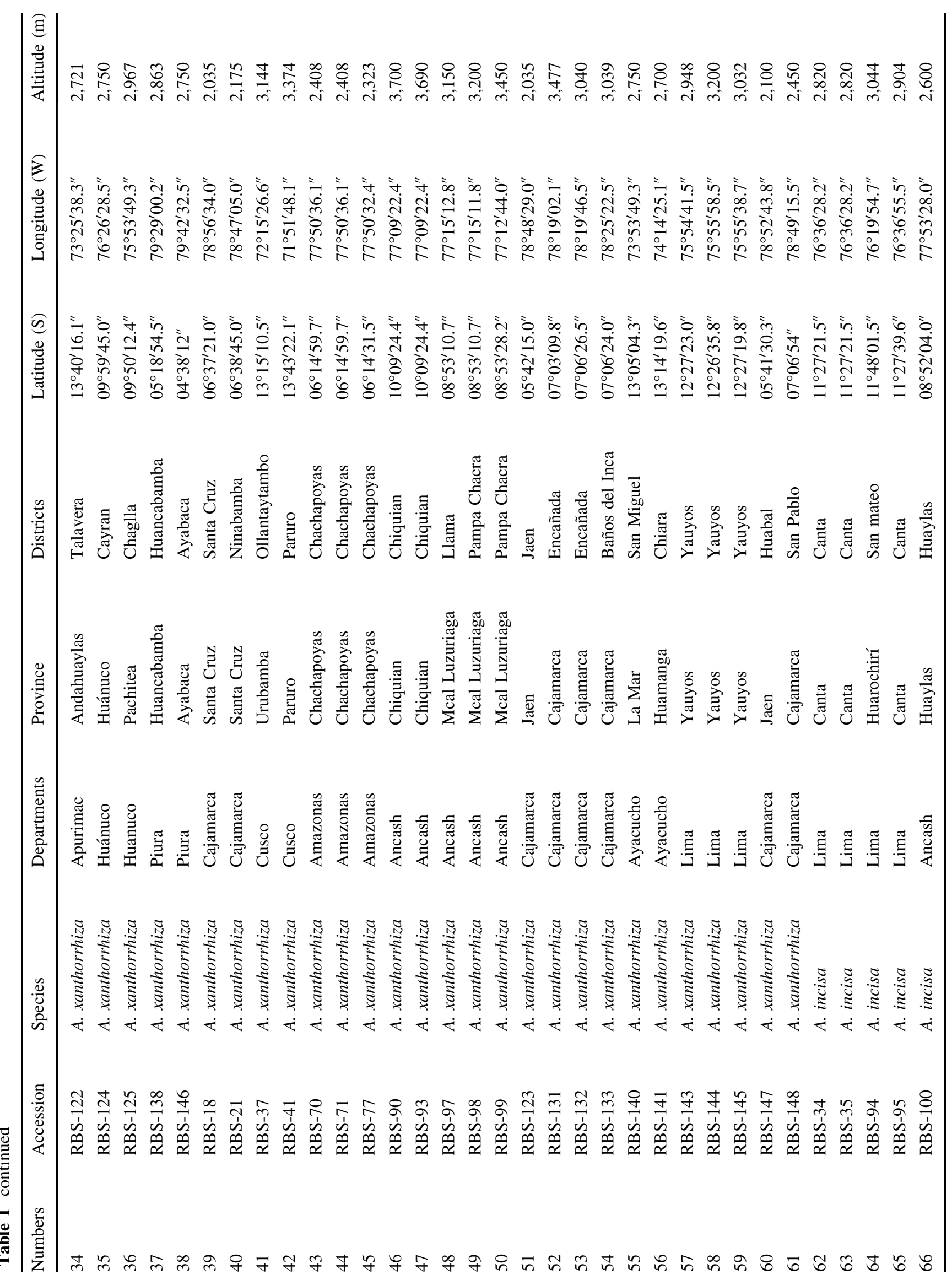




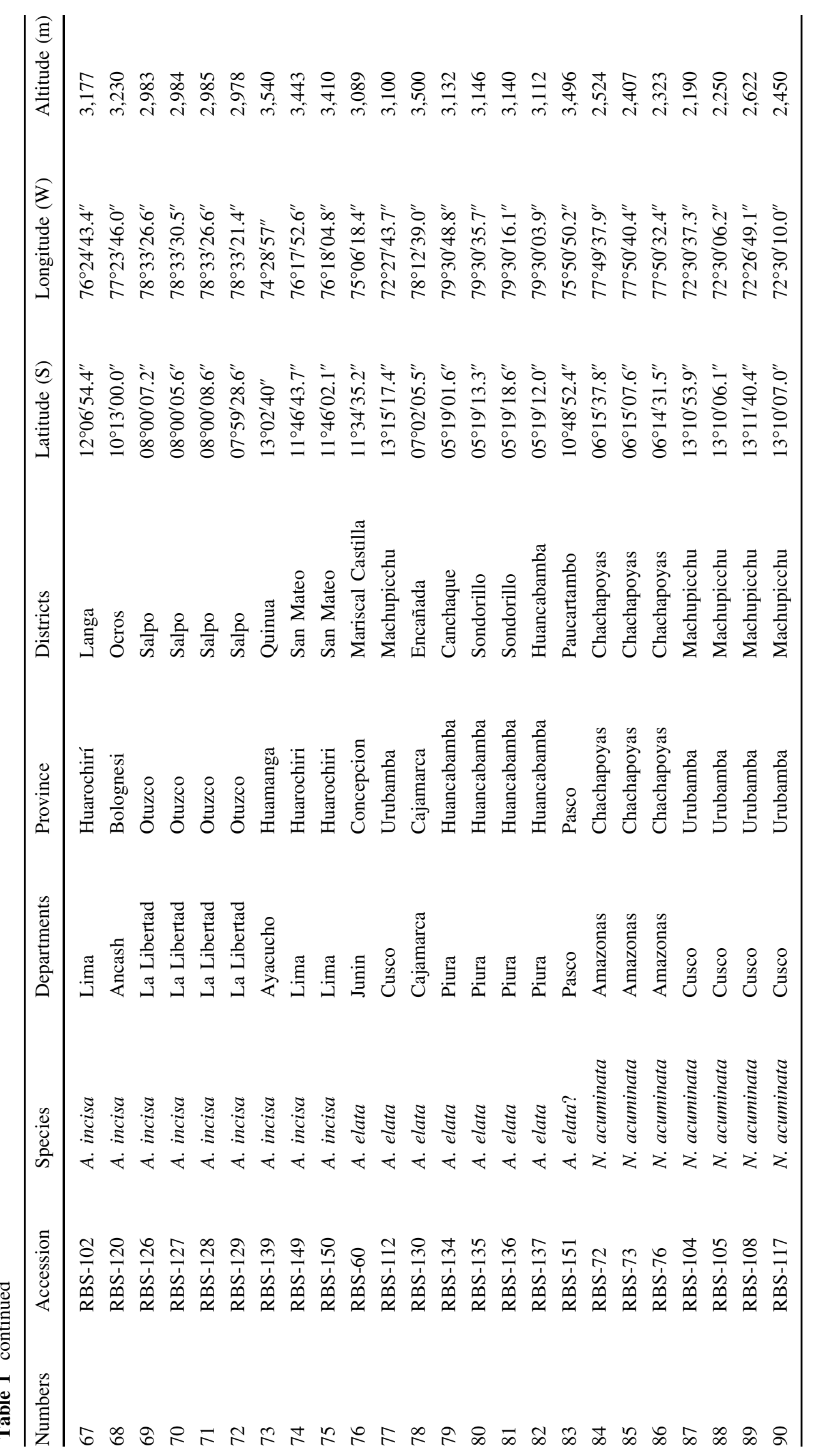


Table 2 The 28 selected morphological descriptors used in the wild Arracacia analysis

\section{Descriptors}

Cormels and rootstock

Life form: 1 monocarpic, 2 polycarpic

Cormels or branches presence: 0 absent, 1 present (1or 2 cormels), 2 ( $>2$ cormels) (determined in the field at sampling time)

Cormels shape: 1 hole long tube, 2 conic, 3 ovoid, 4 oblong, 5 oblong long, 6 oblong divided

Rootstock shape: 1 hole long tube (root-stock absent), 2 conic 3 oblong-divided, 4 oblong long divided, 5 oblong with few cormels, 6 oblong with many cormels

Leaves

Acumen leaflet shape: 1subacute, 2 acute, 3 largely acute

Leaflet adaxial surface (hairs presence): 1 glabra, 2 only in veins, 3 squamose

Leaflet shape: 1 triangular-ovate, 2 ovate-oblong, 3 ovatelanceolate, 4 lanceolate

Leaflet division (incision of terminal leaflet or lobule): 1 superficial, 2 medium 3 deeply incised

Leaflet margin: 1 mucronate-serrate, 2 serrate, 3 serratespinulose

Inflorescence and fruit

Involucel form: 1 entire conic, 2 oblong-linear 3 ovateacuminate, 4 ovate with wing sheathing, 5 oblonglanceolate, 6 ovate-lanceolate, 7 long linear

Involucel length (mm)

Involucel width (mm)

Number of rays/umbels

Ray length (cm)

Umbel form: 1 elongated flat, 2 flat, 3 conic flat

Generative shoot $(\mathrm{GS})$ length $(\mathrm{cm})$

GS number/plant

Petal color: 1 greenish, 2 reddish brown, 3 dark-purple

Stylopodium shape: 1 pyramidal, 2 depressed

Number of umbels/GS

Pedicel length (mm)

Number of grains/GS

Carpophore: 1 bi-parted at 1/4, 2 bi-parted to base

Seed length $(\mathrm{mm})$

Seed width $(\mathrm{mm})$

Mericarp transection: 1 semi-rounded, 2 pentagon

Fruit shape: 1 rounded, 2 conic, 3 ovoid, 4 ovoid-oblong, 5 cordate

Storage root

Predominant storage root flesh color: 1 white, 2 yellow, 3 purple

Source: adapted from Blas (2005) groups at 2.0 taxonomic distance (Fig. 1). The first group includes the species without storage roots, corresponding to A. elata and N. acuminata, and the second group includes species with storage roots, corresponding to A. xanthorrhiza and A. incisa.

States of qualitative characters are shown in Table 3, while basic descriptive statistics of quantitative characters are shown in Table 4. Highvariation coefficients of the quantitative traits are expected due to their measurement directly in situ.

\section{Species without storage roots}

The first group of species was divided into two subgroups: N. acuminata and A. elata. N. acuminata was isolated from all Arracacia species. This taxon is often confused with A. elata and also classified as A. acuminata Benth (Knudsen 2003). Except for A. elata, $N$. acuminata is unlikely to be confused with any other Peruvian Arracacia species. Both species share similar leaf and leaflet forms, incision and size of leaflet, greenish and white flowers, and sprawling habit. However, the filiform involucel and broad cordate fruit of $N$. acuminata are two characters which separate the taxon from A. elata (Fig. 2a, b). $N$. acuminata was first described as A. acuminata Benth, but later transferred to the genus Neonelsonia J.M. Coulter et Rose. Constance (1949) and Mathias and Constance (1962) maintained this view, whereas Knudsen (2003) included the genus in Arracacia. We agree with the maintenance of Neonelsonia, since the two characters - cordate fruit and long filiform involucel - are not considered in the taxonomical key of Arracacia (Mathias and Constance 1962).

Arracacia elata is not likely to be confused with any of the Peruvian Arracacia species. In general, A. elata displays spinulose-serrate leaflet margin, ovoid fruit with acute apex, and ovate-lanceolate involucel.

In A. elata, there is one accession, RBS-151, showing differences from the other populations, i.e., serrate and revolute leaflet margin, white adaxial leaflet, and plant size $(1.5-2 \mathrm{~m})$; nevertheless this accession shares the same habitat as the other populations of A. elata (e.g., they prefer the eastern humid highland, especially in permanently humid riparian vegetation). 
Fig. 1 Dendrogram elaborated from 83 Arracacia and seven Neonelsonia acuminata accessions, and 28 morphological descriptors

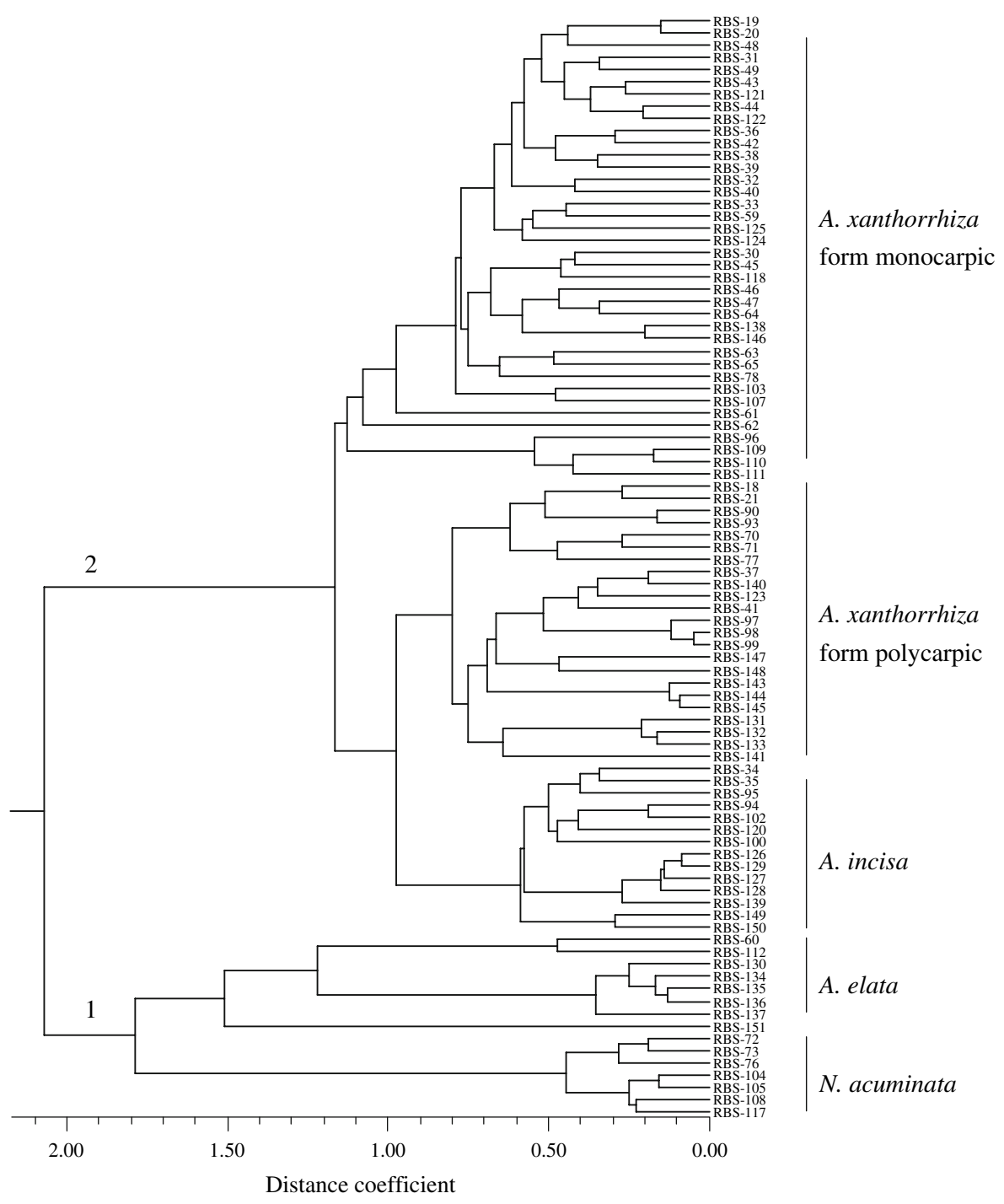

Species with tuberous roots

In species with tuberous roots (A. incisa and $A$. xanthorrhiza), two sub-groups were found: monocarpic and polycarpic forms. Monocarpic plants die once they have flowered and produced fruits, although it may take several years before they develop the first generative shoots. In contrast, polycarpic plants of Arracacia are perennials. They flower and fruit many times (Hermann 1997). Cultivated arracacha genotypes from inter-Andean valleys have been observed to grow during 4-5 years in backyard gardens (Blas 2005). According to the same author, monocarpic wild Arracacia plants produce a large amount of seeds $(394 \pm 265 /$ generative shoot), one or two cormels, and size of the generative shoot is tall $(140 \pm 40 \mathrm{~cm})$. In contrast, the polycarpic plants produce a moderate to low amount of seeds (101 $\pm 55 /$ generative shoot), have well developed cormels and rootstocks, and medium size of generative shoot $(101 \pm 36 \mathrm{~cm})$ (Tables 3,4$)$. This type of classification should be analyzed further in the same ecological conditions, in order to evaluate the expression and behavior of these characters within and between Peruvian Arracacia species.

Within the polycarpic form, two groups were found: a first group corresponding to 14 accessions of A. incisa, and a second group corresponding to 23 accessions of the $A$. xanthorrhiza wild form. The presence of $A$. incisa within the polycarpic form supports the view that it is closely related to $A$. xanthorrhiza through the shared compressed basal stem structures (cormels), the ramification of the flowering stem and the perennial growth habit 
Table 3 States of 17 qualitative characters in each analyzed Arracacia species and Neonelsonia acuminata

\begin{tabular}{|c|c|c|c|c|c|c|c|c|c|c|c|c|c|c|c|c|c|}
\hline \multirow[t]{2}{*}{ Species } & \multicolumn{17}{|c|}{ Qualitative characters $^{\mathrm{a}}$} \\
\hline & 1 & 2 & 3 & 4 & 5 & 6 & 7 & 8 & 9 & 10 & 15 & 18 & 19 & 23 & 26 & 27 & 28 \\
\hline A. xanthorrhiza monocarpic form & 1 & 1 & 2,3 & 2 & 2,3 & 2 & $2,3,4$ & 2,3 & 2 & 1,2 & 3 & 2,3 & 2 & 2 & 2 & 3 & 1,2 \\
\hline A. xanthorrhiza polycarpic form & 2 & 2 & 5,6 & 4,5 & 2,3 & 2 & $1,2,3,4$ & 2,3 & 2 & $1,2,3$ & 2,3 & $1,2,3$ & 2 & 2 & 2 & 3,4 & 1 \\
\hline A. incisa & 2 & 2 & 4,5 & 3,4 & 1,2 & 2 & 1,2 & 2,1 & 2 & 3,4 & 2 & 2,3 & 2 & 2 & 2 & 1 & 1 \\
\hline A. elata & 2 & 0 & 1 & 1 & 3 & 1 & 4 & 3 & 3 & 5 & 1 & 1 & 1 & 1 & 1 & 2 & 1 \\
\hline N. acuminata & 2 & 0 & 1 & 1 & 2 & 1 & 2 & 2 & 1 & 7 & 1 & 5,6 & 1 & 1 & 1 & 5 & 1 \\
\hline
\end{tabular}

${ }^{\mathrm{a}}$ Character numbers and their state according to Table 2 (see Materials and methods)

(Table 3). A. incisa can be distinguished by the length of the involucel which exceeds the flower, the conspicuously scarious margins, and the semirounded seeds. In addition, A. incisa is characterized by a short plant size, combining short petioles and small and incised leaflets (Fig. 2c). Additionally, the taxon is geographically isolated, being present in hilly and dry areas of the Peruvian eastern and central highlands of Quechua region, while A. xanthorrhiza is growing along the eastern, inter-Andean valleys and western Peruvian highlands.

Within the monocarpic form, 38 accessions are very close together and form a cluster in the dendrogram (Fig. 1). The A. xanthorrhiza monocarpic form differs from the A. xanthorrhiza polycarpic form by the root dying away after the end of flowering, the presence of one (rarely 2) cormel and one (rarely 2) reproductive shoot per plant. In addition, the reproductive shoot is very vigorous and shows many ramifications that carry up to 1,000 seeds (Table 4).

Arracacia xanthorrhiza polycarpic form is related to A. xanthorrhiza monocarpic form, but differs in some characters: the presence of cormels with several shoots, the few umbels or low amount of seeds/ generative shoot, the short plant size, and the perennial behavior (Fig. 2d, e).

Also, A. xanthorrhiza polycarpic form appears to be the most closely related to $A$. xanthorrhiza cultivated form, sharing a perennial habit and similar ramifications of the flowering shoot, leaves, involucel, and fruit shape (Blas 2005; Blas et al. 2007). But, A. xanthorrhiza polycarpic form differs from $A$. xanthorrhiza cultivated form, in having few and small cormels, and often a splitting fibrous root (Fig. 2e, f).
According to this analysis, three species from Peru were clearly identified inside the Arracacia genus: $A$. elata, A. incisa, and A. xanthorrhiza (including: monocarpic and polycarpic wild forms).

Geographic distribution of Arracacia genus in Peru

The geographic distribution of the four species $A$. elata, A. incisa, A. xanthorrhiza, and N. acuminata according to latitude, longitude, and altitude data is indicated in Figs. 3 and 4. Collections of the Arracacia genus in Peru cover an altitudinal range from 2,035 to 4,050 m, from the Department of Piura $\left(04^{\circ} 38^{\prime} 12.0^{\prime \prime} \mathrm{S}\right)$ to Cuzco $\left(13^{\circ} 56^{\prime} 25.1^{\prime \prime} \mathrm{S}\right)$. This extensive altitudinal distribution involves four natural regions classified by Pulgar (1987) as: Yunga (5002,300 m), Quechua (2,300-3,500 m), Suni (3,500$4,000 \mathrm{~m})$, and Jalca $(4,000-4,800 \mathrm{~m})$. The most favorable environment for arracacha growth is between the Yunga and Quechua regions, mainly in the Eastern and Western side of the Andes and in the inter-Andean valleys.

The higher percentage of the Arracacia accessions come from the Quechua region, representing $81 \%$ of the total number of analyzed accessions, while the regions Suni, Yunga, and Puna represent 10, 8, and $1 \%$, respectively (Fig. 4). This is in agreement with Pulgar's observation (1987), who considered arracacha as an indicator plant for the Quechua region. In general, in this region the predominant climate is temperate, with significant differences between day and night temperatures. The annual average temperature fluctuates between 11 and $16^{\circ} \mathrm{C}$, the maximum temperature between 22 and $29^{\circ} \mathrm{C}$, and the minimum 


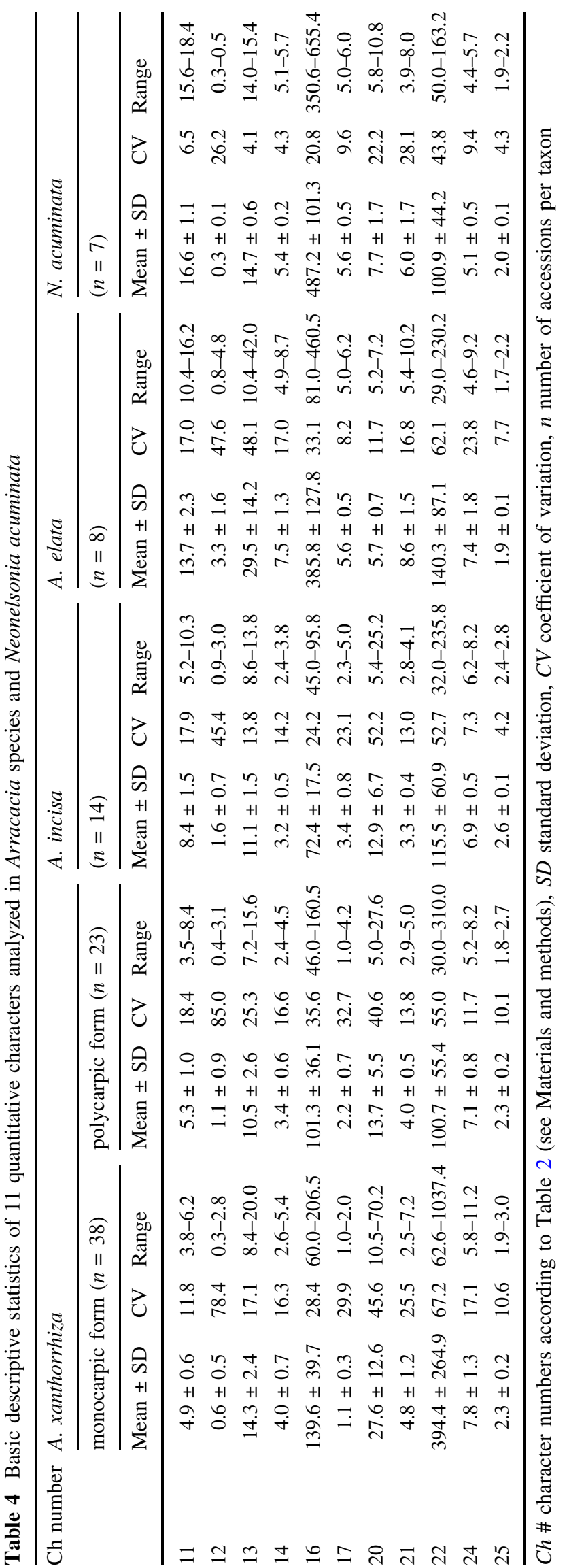

temperature during the winter between -4 and $7^{\circ} \mathrm{C}$. The latter occurs between May and August. During the sunny days, the temperature is high under shade conditions, with temperatures higher than $20^{\circ} \mathrm{C}$; but the nights are fresh, with temperature lower than $10^{\circ} \mathrm{C}$. Elevations over 3,200 $\mathrm{m}$ are known as the limit of the winter frosts, which take place by the alteration of days with strong solar radiation and calm nights of transparent sky with temperatures below $0^{\circ} \mathrm{C}$ (Pulgar 1987). The region Quechua offers some advantages for the life development, such as: good climate, better soils for cultivation, water for irrigation, and great amounts of firewood.

Altitudinal distribution patterns of wild arracacha are very variable (Fig. 4). A. xanthorrhiza, with both monocarpic and polycarpic forms, is mainly found between 2,000 and $4,000 \mathrm{~m}, A$. incisa is also found between 2,000 and $4,000 \mathrm{~m}$, A. elata is present between 3,000 and $4,000 \mathrm{~m}$, and $N$. acuminata is present between 2,000 and 3,000 m. Considering the different altitudinal adaptation of the various collected materials and the very wide ecological conditions prevailing in their distribution areas, it will be possible to identify genotypes characterized by a high level of tolerance to frost and drought conditions.

\section{Climatic characteristics}

Two different ecological niches are found for wild Arracacia in Peru. The first ecological niche concerns the dry areas of Western Yunga and Western and inter-Andean valleys of the Quechua region where rainfalls occur from November to March. The second ecological niche concerns the permanent humid regions of the Eastern Quechua and upper forest where A. elata is particularly well adapted.

In the first niche, some wild species, such as $A$. incisa and A. xanthorrhiza, are present. Apparently, the Arracacia specimens growing in this region are characterized by some dormancy type: during the seven dry months prevailing in this region, plants remain dormant until the next rainy season. The large storage root, rootstock, and cormels may help explain this survival ability. In addition, the floral biology is affected by the environmental factors such as water, nutrients, temperature, and light. Under some stress of these factors (e.g., poor soil fertility, drought, and 
Fig. 2 Vegetative and generative structures of Arracacia elata (a), Neonelsonia acuminata (b) Arracacia incisa (c), and Arracacia xanthorrhiza [wild forms: monocarpic form (d) and polycarpic form (e) and cultivated form (f)]

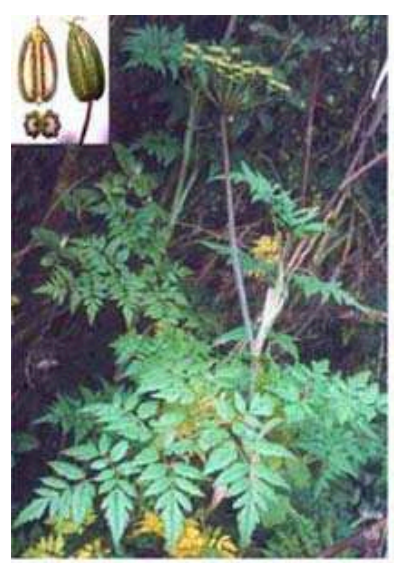

a Leaf, umbel and fruits of A. elata

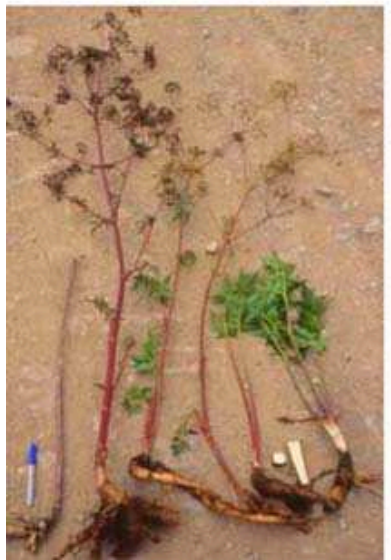
$\frac{\text { d Monocarpic form }}{\text { Vegetative and generative parts of A. xanthorrhiza wild forms }}$

e Polycarpic form

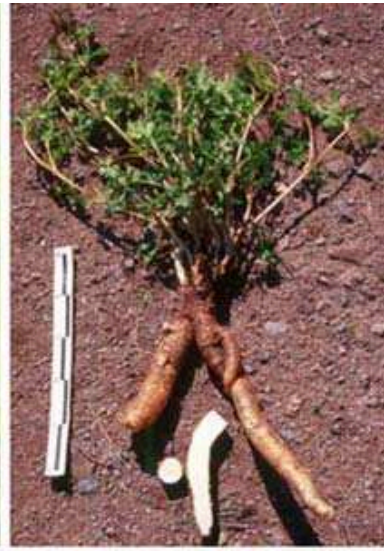

c Vegetative and generative parts of A. incisa

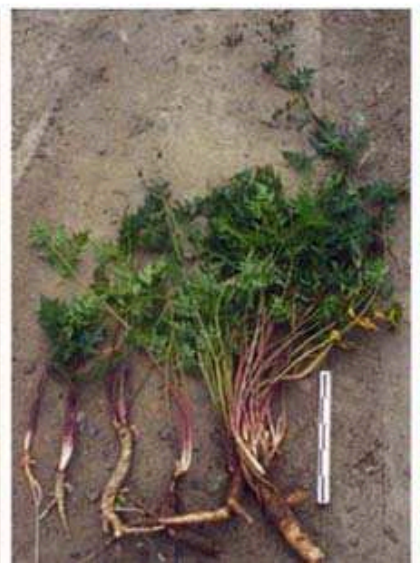

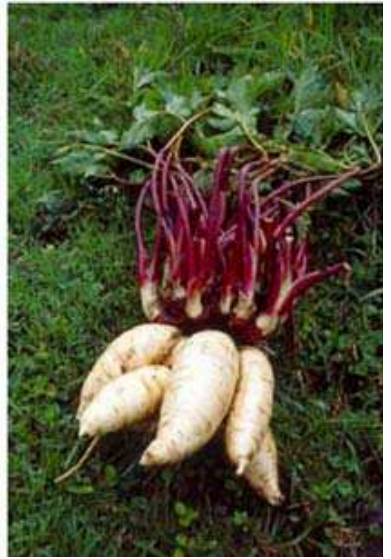

f Storage root, cormels and leaves of $A$. xanthorrhiza cultivated form
Fig. 3 Geographic distribution of Arracacia wild species in Peru

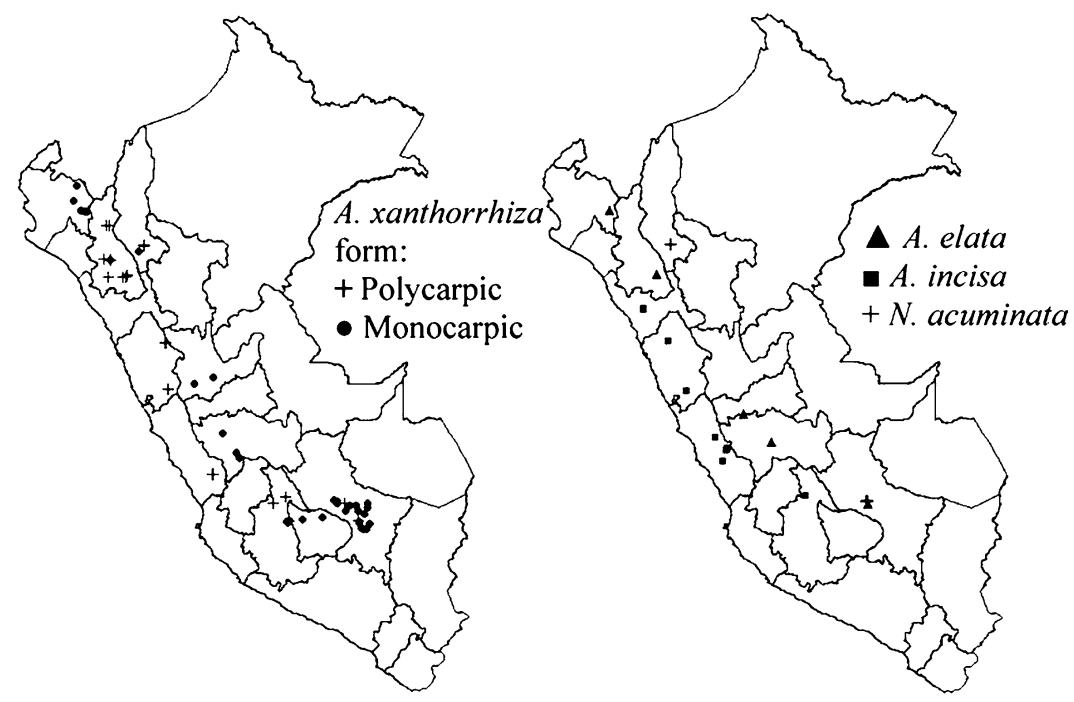

frost), the plants produce a greater proportion of male flowers and fewer hermaphrodite flowers (Salick and Merrick 1990). This could explain presence of andromonoecious plants in Arracacia specimens.
In our main collection of wild arracacha specimens with storage roots, we found a large amount of seeds. Propagation of these species was mainly sexual, and many seedlings were observed during our field survey. 
Fig. 4 Altitudinal distribution of the Arracacia species and Neonelsonia acuminata according to the Peruvian natural regions

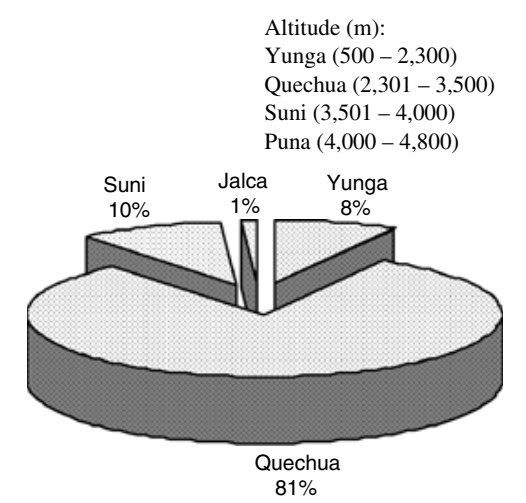

Distribution by regions

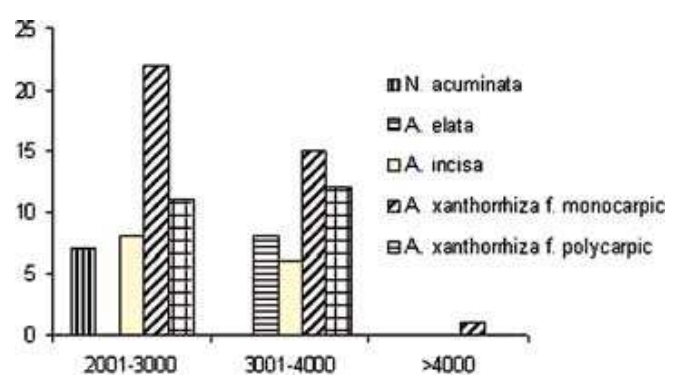

Distribution by species
The areas of wild population distribution are characterized by open fields with or without moderately compact vegetation of shrubs and/or herbaceous plants. Generally, wild arracacha is growing among other shrub plants, like "kishuar" (Buddleja incana Ruiz et Pav.) "chamana" (Dodonaea viscosa Jacq.), and "chilca" (Baccharis lanceolata Kunth); succulent plants from the Bromeliaceae [Aechmea fernandae (E. Morren) Baker, Guzmania claviformis H. Luther, and Tillandsia complanata Bentham], Cactaceae families [Neoraimondia arequipensis (Meyen) Backeb, Opuntia ficus-indica (L.) Mill., and Weberbauerocereus rauhii Backeb.]; and herbaceous plants from: Basellaceae (Ollucus tuberosus
Caldas), Oxalidaceae [Oxalis dombeii St. Hil., $O$. herrerae (L.) Waterman, $O$. tuberosa Molina, and $O$. weberbaueri Diels], Poaceae [Stipa ichu (Ruiz et Pav.) Kunth.], Solanaceae [Lycopersicon peruvianum (L.) Mill., Nicotiana undulata Ruiz et Pav., Solanum nitidum Ruiz et Pav., S. acaule Bitter, and S. albicans Ochoa], and Tropaeolaceae (Tropaeolum bicolor Ruiz et Pav., T. cochabambae Buchenau, T. minus L., and T. tuberosum Ruiz et Pav.).

The second ecological niche concerns the permanent humid regions of the Eastern Quechua and upper forest where A. elata is particularly well adapted. Specimens of this species do not have tuberous storage roots and the aerial parts are vigorous and tall
Fig. 5 Climatic data corresponding to the regions of Arracacia accessions distribution. a Distribution of Arracacia accessions according to temperature and rainfall. b Distribution frequencies of Arracacia accessions according to rainfall. c Distribution frequencies of Arracacia accessions according to temperature

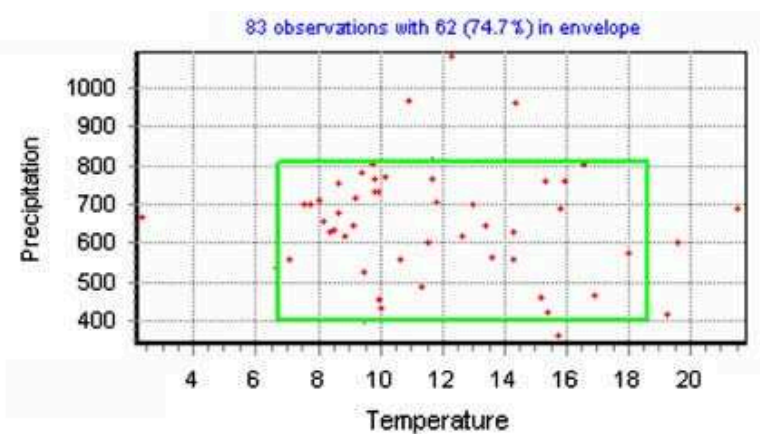

a Distribution of Arracacia accessions according to temperature and rainfall

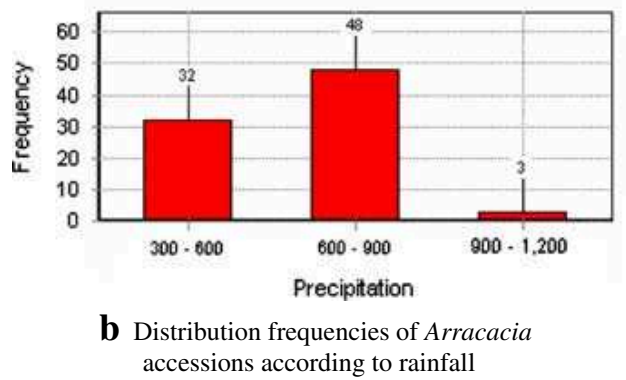

accessions according to rainfall

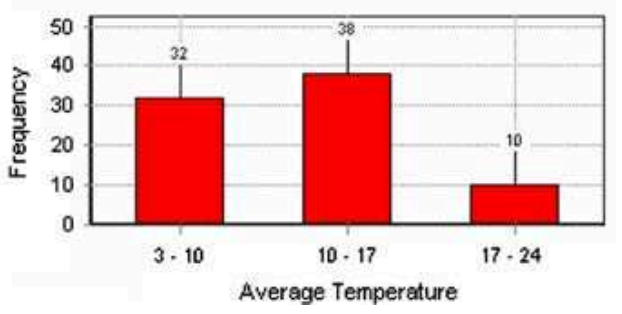

c Distribution frequencies of Arracacia accessions according to temperature 
$(4 \pm 1 \mathrm{~m})$. A. elata genotypes are setting many seeds $(140 \pm 87$ seeds/generative shoot according to Table 4), but vegetative propagation through adventitious root formation of the creeping stem is also observed. So, in A. elata there is both sexual and asexual propagation, although the seed dispersal seems to be more important. Specimens were usually found along the riverbanks in the cloudy Eastern highlands, alongside compact vegetation.

According to our field surveys, wild arracacha is mainly distributed in rural communities and near small villages in the mountainous Quechua and Suni regions. In some places, the wild arracacha is considered as a weed, e.g., in Apurimac, Cajamarca, and Cusco Departments. But in general, the wild forms are not considered as invasive. According to our observations, wild arracacha is not presently threatened directly by human activities. Indeed, in this region, agricultural activities are characterized by traditional and subsistence farming, with very little or no connection to markets.

According to the climatic data, $75 \%$ of the evaluated accessions come from regions where the average temperature ranges from 7 to $19^{\circ} \mathrm{C}$ and the rainfall varies from 400 to $810 \mathrm{~mm}$ (Fig. 5a). While $39 \%$ of the accessions grow between 300 and $600 \mathrm{~mm}$, more than $57 \%$ of the accessions grow between 600 and $900 \mathrm{~mm}$ and $<4 \%$ are present between 900 and 1,200 mm (Fig. 5b). Concerning the temperature range, $39 \%$ of the accessions are present in areas where average temperature varies between 2 and $10^{\circ} \mathrm{C}, 46 \%$ in areas where average temperature varies between 10 and $17^{\circ} \mathrm{C}$, and $12 \%$ in areas where average temperature varies between 17 and $24^{\circ} \mathrm{C}$ (Fig. 5c). Such data could also be useful to establish strategies for in situ and ex situ germplasm management in Peru. Up to now, data on the precise distribution of Arracacia in the Andean region were lacking. No accurate distribution map of Arracacia species has been published.

\section{Conclusions}

Clustering 90 accessions (including wild Arracacia spp. and N. acuminata) with the 28 selected descriptors, showed two main groups. The first group includes the species without storage roots, corresponding to A. elata and N. acuminata, and the second group includes the species with storage roots, corresponding to A. xanthorrhiza, and A. incisa.

The filiform involucel that extends from the flowers and the broad cordate fruit of $N$. acuminata are two characters which clearly separate this taxon from $A$. elata. In addition, $A$. elata shows spinuloseserrate leaflet margin, ovoid fruit, and ovate-lanceolate involucel.

Species with tuberous roots are divided into monocarpic and polycarpic plants. In the polycarpic plants two species are found: $A$. incisa and the wild form of A. xanthorrhiza, showing the close relationship between the two taxa. In addition, they share the following characteristics: compressed basal stem structures (cormels), the ramification of the flowering stem and the perennial growth habit. On the other hand, A. incisa can be distinguished from $A$. xanthorrhiza by the length of the involucel which exceeds the flower, the conspicuously scarious margins, and the semi-rounded fruits.

Arracacia xanthorrhiza polycarpic form differs from A. xanthorrhiza monocarpic form by the presence of cormels with several shoots, the limited number of umbels or the low amount of seeds/ generative shoot, the short plant size, and the perennial behavior. From these results, three species from Peru are clearly identified inside the Arracacia genus: A. elata, A. incisa, and A. xanthorrhiza (including: monocarpic and polycarpic wild forms). In order to identify the most discriminating characters among the Peruvian accessions collected and measured in situ, it is suggested to compare a representative sample of them together in the same geographical stations.

The most favorable environment for wild arracacha growth is between the Quechua and Suni regions, mainly in the Eastern and Western side of the Andes and in the inter-Andean valleys. However, wild specimens are more frequently found in the Quechua region ( $81 \%$ of accessions). Consequently, the distribution of wild Arracacia species in Peru is characterized by two main ecological zones: (1) a drier zone, like western Yunga and western and interAndean valleys of the Quechua region (with seasonal rain from November to March), where the species $A$. incisa and A. xanthorrhiza are present, and (2) a permanent humid zone, like the Eastern Quechua where A. elata is adapted. Due to this wide distribution, it is expected to identify genotypes more 
adapted or tolerant to drought, humid, and frost conditions. This information could be useful to establish strategies for in situ and ex situ conservation and management of germplasm in the Andean region.

Acknowledgements This research was supported by grants from Coopération Universitaire au Développement (CUD) and Direction Générale de la Cooperation Internationale, Belgium.

\section{References}

Blas R (2005) Diversity of Arracacia species in Peru. Ph.D. Thesis., Gembloux Agricultural University, Belgium, p 154

Blas R, Ghislain M, Herrera MR, Baudoin J-P (2007) Genetic diversity analysis of wild Arracacia species according to morphological and molecular markers. Genet Resour Crop Evol (in press)

Brako L, Zarucchi J (1993) Catálogo de las angiospermas y gimnospermas del Perú. Missouri Bot Gard, p 1286

Constance L (1949) The South American species of Arracacia (Umbelliferae) and some related genera. Bull Tor Bot Club 76(1):39-52

Constance L (1997) An instance of East-West confusion in chinese Umbelliferae, or Arracacia out of Asia. Edinb J Bot 54(1):99-104

Harris JG, Harris MW (2001) Plant identification terminology. An illustrated glossary, 2nd ed. Spring Lake Publishing, Utah, USA, p 206

Hermann M (1997) Arracacha (Arracacia xanthorrhiza Bancroft). In: Hermann M, Heller J (eds) Andean roots and tubers: Ahipa, arracacha, maca and yacon. Promoting the conservation and use of underutilized and neglected crops. 21. Institute of Plant Genetics and Crop Plant Research, Gatersleben/International Plant Genetic Resources Institute, Rome, Italy, p 75-172

Hijmans R, Guarino L, Bussink C, Barrantes I, Rojas E (2002) DIVA-GIS, Version 2. Sistema de Información Geográfica para el Análisis de Datos de Biodiversidad. Manual International Potato Center, Lima, Perú, p 67
Hodge WH (1954) The edible arracacha - a little-known root crop of the Andes. Econ Bot 8(3):195-221

Knudsen SR (2003) Reproduction biology of the Andean root crop arracacha (Arracacia xanthorrhiza Bancroft var. xanthorrhiza) and the taxonomic status of the South American Arracacia Bancroft species with special emphasis on the position of the cultivated arracacha and related wild species. Ph.D., Thesis. Botanical Section, Department of Ecology, The Royal Veterinary and Agricultural University. Copenhagen, Denmark, p 150

Lindley J (1951) Glosología de los términos usados en botánica. Traducido de la versión inglesa y aumentada con la terminología equivalente alemana por J. E. Rothe, Miscelánea $\mathrm{N}^{\circ} 15$. Fundación Miguel Lillo, Instituto Miguel Lillo de la Universidad Nacional de Tucumán. Tucumán, Argentina, p 125

Mathias ME, Constance L (1962) Arracacia Bancroft. In: Mathias ME, Constance L (eds) Flora of Perú. Field Mus Nat Hist Bot 13(1) part V-A:13-19

National Research Council (1989) Arracacha. In: Lost crops of the Incas. Little known plants of the Andes with promise for worldwide cultivation. National Academy Press. Washington DC, p 46-55

Pulgar J (1987) Geografía del Perú. Las ocho Regiones Naturales. Novena Edición. Promoción Editorial Inca, S.A. (PEISA), Lima, Perú, p 244

Rohlf F (1994) NTSYS PC: numerical taxonomy and multivariate analysis for the IBM PC microcomputers (and compatibles), Version 1.80. User Manual. Stony Brook, New York, USA, p 240

Rohlf F (2000) NTSYS PC: numerical taxonomy and multivariate analysis for the IBM PC microcomputers (and compatibles), Version 2.1 User guide. Applied Biostatistics, Stony Brook, New York, USA, p 39

Royal Horticultural Society (RHS) (1995) Colour chart. London, UK

Salick J, Merrick LC (1990) Use and maintenance of genetic resources: crops and their wild relatives. In: Ronald Carroll C, Vandermur JH, Rosset PM (eds) Agroecology. Biological resource management. Mc Graw-Hill, NY, USA, p 517-548 